\title{
Bibliografía comentada
}

La historiografía de la arquitectura moderna Tournikiotis Panayotis. Madrid: Mairea, 2001.

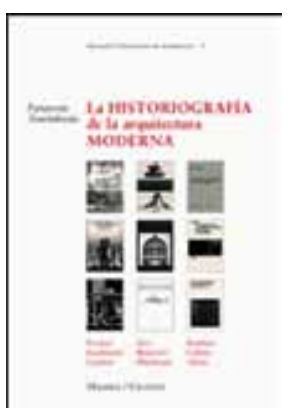

«No hay hechos ni arquitectura: sólo tenemos las narraciones», esta es la tesis que logra desplegar el autor, desde su propuesta de elaboración de una historia del Movimiento Moderno en arquitectura, donde prescinde completamente del estudio de los edificios y los conjuntos urbanos construidos y concentra precisamente el análisis, en los textos, ya doctrinales, que conforman la urdimbre narrativa fundante del discurso arquitectónico moderno, con ello sus firmantes Pevsner, Kaufmann, Giedion, Zevi, Benevolo, Hitchcock, Banham, Collins, Tafuri. La investigación de Tournikiotis, aporta desde el valioso material bibliográfico analizado, una condición que nos permite apreciar una trama textual que nos constituye como arquitectos; querámoslo o no, sepámoslo o no, la arquitectura pertenece también al ámbito del discurso y con ello sus implicancias radicales. Así, el texto nos permite comprender la abismal dicotomía que hay entre lo conceptual y lo concreto, y con ello, nos ayuda a establecer los términos en los que se ha fundamentado la historicidad de los espacios-formas de la arquitectura moderna. La arquitectura como narración desplegada, aniquila la ufana concretitud o factualidad en la que ingenuamente suele pretender situarse el hacer del arquitecto.

Escritos 1919-1920. La corona de la ciudad Bruno Taut. Madrid: El Croquis, 1997.

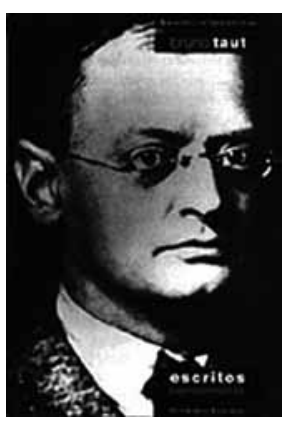

La importante influencia de los escritos de Bruno Taut, marcan un programa que abogará por los lineamientos de una arquitectura del futuro, más humana y más social que la del pasado, que será referente fundamental del programa de trabajo formulado por Walter Gropius en abril de 1919 para la Bauhaus de Weimar, por ello ayudaron a definir la nueva responsabilidad del arquitecto ante la sociedad, su compromiso con el edificio y con la ciudad.
El texto de Taut busca explicitar el pensamiento social, como corona para la ciudad, posando su posibilidad de fundamento en la acción de la comunidad. El sentido de comunidad llamemos, es la condición para Taut de toda arquitectura, a la vez que, reconoce su falta en la Ciudad Nueva, con ello, la ausencia de representación de nuestros más profundos sentimientos con respecto a los hombres y al mundo: «El arquitecto es quien tiene que dar forma a esa idea, sino quiere convertirse en superfluo y si desea saber para qué vive. ¿De qué sirve al fin y al cabo hacer alguna que otra casita o edificio bonito, si no conocemos la fuente principal de la que manan todos los arroyos? (...) Si no poseen el conocimiento de su objetivo final, si ni siquiera intuyen los más sublimes anhelos y esperanzas, entonces su existencia carece de valor».

La Corona de la Ciudad de Taut, es un texto que dispone una problemática profundamente contemporánea de Sentido (o ausencia de él), su vigencia pasa por interrogar la posibilidad del Espacio Común de la ciudad, diferente al espacio público (contrapartida nacida al alero del espacio privado económico del siglo xVIII), donde la comunidad en su espacio es simplemente el estar de sus singularidades, el estar suspendido en su límite -léase bien- es la inoperancia de la obra económica, técnica e institucional. En definitiva, espacios de la ciudad que no responden a lógicas operativas, ni funcionales, sino a la des-obra (sin obras).

Los ojos de la piel

Juhani Pallasmaa. Barcelona: Gustavo Gili, 2006.

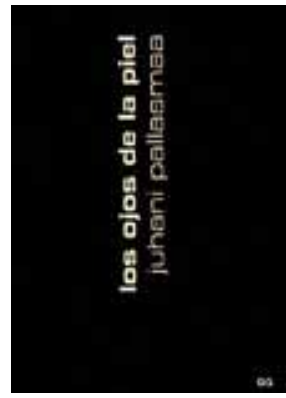

«El hecho de que, generalmente, el lenguaje del Movimiento Moderno no haya sido capaz de penetrar la superficie del gusto y de los valores populares parece deberse a su énfasis intelectual y visual unilateral; en general, el proyecto moderno ha albergado el intelecto y el ojo, pero ha dejado sin hogar al cuerpo y al resto de sentidos, así como a nuestros recuerdos, nuestros sueños y nuestra imaginación». El texto de Pallasmaa aborda desde un contexto mayor de debate, la cada vez más denunciada, sujeción general de la sociedad occidental al paradigma ocularcentrista y su consecuente parcialización cognitiva en la aprehensión de la realidad. Para nosotros, en particular, la omnipresente arquitectura retiniana actual, con sus valores de transparencia, sensaciones de ingravidez y de flotación entre otros, debilitan precisamente las posibilidades físicas, sensuales y corpóreas propias de la concretitud de la obra arquitectónica y con ello, conllevan una especie de de-sensualización y des-erotización escalofriante de las relaciones humanas con la realidad. Lo dispuesto por Pallasmaa en su libro, de la mano de importantes pensadores contemporáneos, conlleva la fuerte tensión que surge de la reflexión del cómo pensamos y cómo sentimos, lo cual se presenta adscrito a un modo histórico y por ello en lo tocante respecto a las emociones -nos dirá Martin Heidegger- no hemos dado un solo paso más allá de Aristóteles en dos mil años. Desde aquí, la apertura de todo un nuevo mundo para pensar arquitectura.

Ledoux con Kant. Prólogo a la edición francesa Hubert Damisch. En: Emil Kaufmann. La arquitectura de la llustración: Barroco y posbarroco en Inglaterra, Italia y Francia. Madrid: Gustavo Gili, 1995.

El prólogo a la edición francesa del texto de Emil Kaufmann, que el teórico del arte Hubert Damisch elabora, es un texto fundamental para profundizar y contextualizar los grandes cambios intelectuales que propiciaron el desarrollo de una arquitectura como la del Movimiento Moderno. Surge una nueva arquitectura porque precisamente emerge mucho antes un modo radicalmente diferente de aprehensión de la realidad. «Kant a quien el texto de Kaufmann hace referencia desde su primera página».

Es porque Emil Kaufmann tiene en todo momento en cuenta el potente y revolucionario pensamiento kantiano, es porque puede afirmar la validez de una arquitectura autónoma y con ello detectar ya en Étienne-Louis Boullée, Claude Nicolas Ledoux y Jaques Lequeu, arquitectos franceses de la Revolución, el germen de una autonomía disciplinar, que alentara y acompañara en gran parte las búsquedas estéticas de los arquitectos modernos. Adentrarse en el pensamiento kantiano es un necesario modo para comprender la estética moderna, pero aún más, los discursos filosóficos posmodernos, que alientan en gran medida la producción de muchos arquitectos y artistas contemporáneos. 